NASA/TM-2005-213593

\title{
The Influence of Viscous Effects on Ice Accretion Prediction and Airfoil Performance Predictions
}

Richard E. Kreeger

Glenn Research Center, Cleveland, Ohio

William B. Wright

QSS Group, Inc., Cleveland, Ohio 
Since its founding, NASA has been dedicated to the advancement of aeronautics and space science. The NASA Scientific and Technical Information (STI) Program Office plays a key part in helping NASA maintain this important role.

The NASA STI Program Office is operated by Langley Research Center, the Lead Center for NASA's scientific and technical information. The NASA STI Program Office provides access to the NASA STI Database, the largest collection of aeronautical and space science STI in the world. The Program Office is also NASA's institutional mechanism for disseminating the results of its research and development activities. These results are published by NASA in the NASA STI Report Series, which includes the following report types:

- TECHNICAL PUBLICATION. Reports of completed research or a major significant phase of research that present the results of NASA programs and include extensive data or theoretical analysis. Includes compilations of significant scientific and technical data and information deemed to be of continuing reference value. NASA's counterpart of peerreviewed formal professional papers but has less stringent limitations on manuscript length and extent of graphic presentations.

- TECHNICAL MEMORANDUM. Scientific and technical findings that are preliminary or of specialized interest, e.g., quick release reports, working papers, and bibliographies that contain minimal annotation. Does not contain extensive analysis.

- CONTRACTOR REPORT. Scientific and technical findings by NASA-sponsored contractors and grantees.
- CONFERENCE PUBLICATION. Collected papers from scientific and technical conferences, symposia, seminars, or other meetings sponsored or cosponsored by NASA.

- SPECIAL PUBLICATION. Scientific, technical, or historical information from NASA programs, projects, and missions, often concerned with subjects having substantial public interest.

- TECHNICAL TRANSLATION. Englishlanguage translations of foreign scientific and technical material pertinent to NASA's mission.

Specialized services that complement the STI Program Office's diverse offerings include creating custom thesauri, building customized databases, organizing and publishing research results ... even providing videos.

For more information about the NASA STI Program Office, see the following:

- Access the NASA STI Program Home Page at http://www.sti.nasa.gov

- E-mail your question via the Internet to help@sti.nasa.gov

- Fax your question to the NASA Access Help Desk at 301-621-0134

- Telephone the NASA Access Help Desk at 301-621-0390

- Write to:

NASA Access Help Desk

NASA Center for AeroSpace Information 7121 Standard Drive

Hanover, MD 21076 
NASA/TM-2005-213593

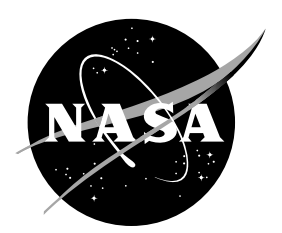

\section{The Influence of Viscous Effects on Ice Accretion Prediction and Airfoil Performance Predictions}

Richard E. Kreeger

Glenn Research Center, Cleveland, Ohio

William B. Wright

QSS Group, Inc., Cleveland, Ohio

Prepared for the

43rd Aerospace Sciences Meeting and Exhibit

sponsored by the American Institute of Aeronautics and Astronautics

Reno, Nevada, January 10-13, 2005

National Aeronautics and

Space Administration

Glenn Research Center 
Available from

NASA Center for Aerospace Information 7121 Standard Drive

Hanover, MD 21076
National Technical Information Service 5285 Port Royal Road Springfield, VA 22100

Available electronically at http://gltrs.grc.nasa.gov 


\title{
The Influence of Viscous Effects on Ice Accretion Prediction and Airfoil Performance Predictions
}

\author{
Richard E. Kreeger \\ National Aeronautics and Space Administration \\ Glenn Research Center \\ Cleveland, Ohio 44135 \\ William B. Wright \\ QSS Group, Inc. \\ Cleveland, Ohio 44135
}

\begin{abstract}
A computational study was conducted to evaluate the effectiveness of using a viscous flow solution in an ice accretion code and the resulting accuracy of aerodynamic performance prediction. Ice shapes were obtained for one single-element and one multi-element airfoil using both potential flow and Navier-Stokes flowfields in the LEWICE ice accretion code. Aerodynamics were then calculated using a Navier-Stokes flow solver.
\end{abstract}

\section{Nomenclature}

$2 \mathrm{D}$

$\mathrm{Cd}$

CFD

$\mathrm{Cl}$

$\mathrm{Cp}$

LWC

MVD

$\mathrm{M}$

RANS

RN

S-A

$\mathrm{V}_{\text {INF }}$ two-dimensional

section drag coefficient

computational fluid dynamics

section lift coefficient

pressure coefficient

liquid water content

median volume diameter

Mach number

Reynolds-Averaged Navier Stokes

Reynolds number

Spalart-Almaras

freestream velocity

angle of attack

\section{Introduction}

\begin{abstract}
A CCRETION prediction codes are improving their accuracy and productivity, yet some recognized shortcomings remain. Flowfields where viscous and unsteady effects are important may not be modeled correctly, such as cases where large regions of separated flow are present. These situations can occur in a variety of scenarios likely to contain the critical ice shape- large glaze ice horns, high angles of attack, and also in multielement airfoils. With airfoil performance as a criteria, the trade between accuracy and effort still remains a question. Attempts to determine the usefulness of Navier-Stokes flow solutions in ice accretion prediction have only recently begun. This paper begins to address whether the additional effort of implementing a computational fluid dynamics (CFD) flow solver solution into the ice accretion process is truly significant in terms of performance degradation.

While NASA has integrated a Navier-Stokes flow solver with its primary ice accretion code, LEWICE ${ }^{1}$, validation to date is somewhat limited, and results appear mixed. The question of whether the improvements in the predicted ice shapes warrant the additional computational expense has not been fully addressed. Further study is needed to determine if these improvements are significant in terms of performance degradation.

With plans to incorporate a Navier-Stokes flow solver more directly into the ice accretion and droplet trajectory modules of an ice accretion code, it is important to quantify the gain in performance degradation accuracy that can be obtained. This will help NASA decide how tightly or loosely coupled the future generation of codes should be with the thermodynamic, trajectory and multi-phase elements of ice accretion prediction.
\end{abstract}




\section{Single Element Airfoil}

A classical symmetric airfoil was chosen for the initial single-element phase of this study. A NACA 0012 airfoil section at 3.5 degrees angle of attack and a flight speed of $102.8 \mathrm{~m} / \mathrm{sec}$ was used. The chord length was $0.5334 \mathrm{~m}$. These conditions correspond to a freestream Mach number of 0.324 and a Reynold's number of 2,400,000. The static temperature was $250.37 \mathrm{~K}$ and the static pressure was $100,000 \mathrm{~N} / \mathrm{m}^{2}$. The icing conditions were selected from the LEWICE validation database, and correspond to a seven-minute exposure in rime ice conditions. A median volume diameter of $20 \mu$ and a liquid water content of $0.55 \mathrm{~g} / \mathrm{m}^{3}$ were chosen.

These conditions correspond to run 405 of the 1998 Ice Shape Comparison test. This test to determine experimental ice shapes was conducted in the NASA Glenn Icing Research Tunnel using a model NACA0012 with a 21-inch chord. The ice tracing used for comparison was obtained at a spanwise station of 36-inches.

ICEG2D, the NASA Glenn integrated Navier-Stokes flow solver and ice-accretion code ${ }^{2}$, was then used in batch mode to calculate a 7-minute ice shape. ICEG2D initially distributes points along a user-defined airfoil geometry using a specified number of control points. These points are then automatically clustered in regions of high curvature to ensure geometric fidelity. A NURBS approximation of the iced airfoil is then generated using parameters suitable for either a smooth or rough surface, as defined by the user. A marching algorithm with a parabolic solver is used to generate a structured grid for each icing time step (typically 1 minute).

A single-zone C-type grid with wake cut was developed. A downstream distance of 14 chord lengths was selected for the downstream zone boundary. A non-dimensional distance to the first grid point off the airfoil surface of 0.00001 was used to give a $y+$ value of approximately 1 . Grid quality for the default input values in ICEG2D has already been established ${ }^{3}$ for typical cases.

ICEG2D was run for this case in Level 0 coupling mode. In Level 0 coupling mode, the Navier-Stokes solution is used in place of the panel method solution in LEWICE. This affects both the droplet trajectories and the boundary layer computations in the ice accretion process. ICEG2D automatically supplies the flow solution and grid file needed by LEWICE and sets the appropriate input parameter (IGRID $=1$ ) when Level 0 is specified. The WIND code also provides surface heat transfer information, which can also be included in the ice accretion step through the LEWICE input parameter IHTC. This is known as Level 1 coupling, and also includes the Level 0 process. For the rime shape used in this study, using the surface heat transfer data from WIND did not appear to provide significant improvements over Level 0 . This is not necessarily the case for all ice shapes.

The 7-minute rime ice shape was then compared with the corresponding ice shape developed experimentally in the IRT and with a LEWICE-derived ice shape using potential flow. The ice shapes calculated by ICEG2D are shown at one minute intervals in Figure 1. This demonstrates accurate prediction of ice shape for cold conditions such as this.

Aerodynamic performance was then calculated for the ice shapes derived from Navier-Stokes, potential flow and experiment. A flowfield for the clean airfoil was also computed.

Aerodynamic performance was calculated using WIND ${ }^{4}$, a general-purpose flow solver. WIND is a second-order accurate finitevolume code which solves the Navier-Stokes equations in conservative form. The code has Runge-Kutta and Global Newton schemes for time accurate computations, but for this study the Reynolds Averaged Navier Stokes (RANS) scheme was used.

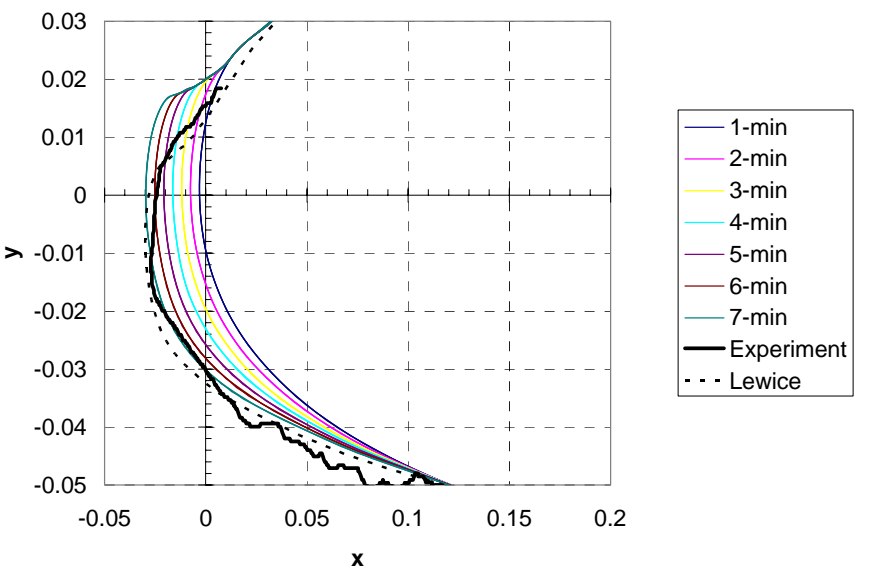

Figure 1. NACA 0012 Ice Shapes

In addition to the flow solver itself, WIND includes a number of associated utilities, and several of these were used. The program $c f c n v t$ converts between the standard PLOT3D format and the $c g d$ format that is specific to WIND. The $c f s u b s e t$ allows a user to manipulate an existing grid by cropping various indices. The utility code gman is used to apply boundary conditions and zone connectivity information to a generic grid prior to input into WIND. 
WIND allows the user to select from a variety of algebraic, one-equation and twoequation turbulence models. The SpalartAlmaras (S-A) one-equation turbulence model $^{5}$ was selected for its robust and general applicability to icing problems ${ }^{6}$. Some initial calculations were also made using the K- $\varepsilon$ model of $\mathrm{Chien}^{7}$, but no significant improvements were found for this case, so the S-A model was used throughout.

The convergence history of the 7-minute ice shape is shown in Figure 2. The number of iterations recommended for use in ICEG2D is 2000 , but for this study solutions were run through 800 cycles of 20 iterations each. Run times to 16,000 iterations on a singleprocessor SGI were typically about $4 \frac{1 / 2}{2}$ hours of CPU time. Convergence of the $\log (\mathrm{L} 2)$

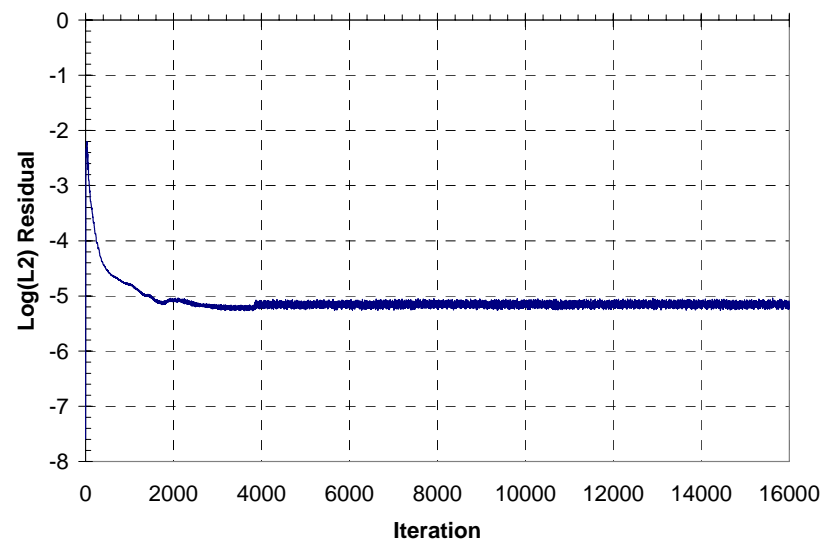

Figure 2. Convergence of NACA0012 Solution residual was typically obtained to the fifth order in significantly less than 16,000 iterations.

Table 1 shows the lift, drag and grid size for the clean, LEWICE, experimental and ICEG2D (taken at 1-minute intervals) solutions.

\begin{tabular}{|l|c|c|c|c|c|c|c|c|c|c|}
\hline & 1-min & 2-min & 3 -min & 4-min & 5 -min & 6-min & 7-min & LEW & EXP & Clean \\
\hline $\mathrm{Cl}$ & 0.39048 & 0.39075 & 0.39083 & 0.39123 & 0.39012 & 0.38806 & 0.38452 & 0.38810 & 0.38325 & $\mathrm{~N} / \mathrm{A}$ \\
\hline $\mathrm{Cd}$ & 0.00342 & 0.00346 & 0.00355 & 0.00359 & 0.00388 & 0.00431 & 0.00496 & 0.00358 & 0.00870 & $\mathrm{~N} / \mathrm{A}$ \\
\hline Grid & $337 \times 101$ & $347 \times 101$ & $345 \times 101$ & $345 \times 101$ & $343 \times 101$ & $339 \times 101$ & $347 \times 101$ & $335 \times 101$ & $455 \times 101$ & $335 \times 101$ \\
\hline
\end{tabular}

Table 1. Section Coefficients Calculated for Single-element Airfoil Performance.

Figures 3,4,5, and 6 show the total velocity field for the four cases. Of particular interest is the roughness in the experimental data and the corresponding effect this has on the section drag coefficient. The surface pressures were also calculated, and these are shown in Figure 7 for the three ice shape methods, along with the clean airfoil surface. Skin friction coefficient for the four cases is shown in Figure 8.

It is now possible to run multiple time steps for single-element airfoils, and suitable results can be obtained for rime ice shapes at low to moderate angles of attack. But the subject still has not been completely investigated, and this paper represents only the preliminary phase of an investigation into the practical uses and applications of Navier-Stokes-coupled ice accretion prediction. The effects of wall temperature boundary condition (Level 1 coupling) will be further investigated, for warm glaze ice shapes in particular. The flow solver itself may suffer from limitations at high angles of attack where available turbulence models don't really handle stall very well ${ }^{8,9}$ More advanced methods, such as DES and LES, need to be investigated further. The benefits of the added coupling may eventually play a role in the development of new or modified roughness models in the boundary layer computations.

\section{Multi-Element Airfoil}

Although a rime ice shape on a single-element airfoil can be a challenging aerodynamic problem to solve, it is not one which necessarily requires a viscous flow solution to obtain satisfactory results. Those ice shapes which are more dominated by viscous effects either exhibit large regions of flow separation caused by massive glaze-ice horns, or occur in airfoils which naturally have regions of reversed or separated flow, such as might occur in multi-element airfoils.

A modern multi-element airfoil in the landing configuration was chosen for the second part of this study. The Douglas/NASA Lewis/NASA Langley Advanced High-Lift Multi-Element Airfoil Program ${ }^{10,11}$ was established in 1993 to improve the understanding of ice accretion effects on multi-element airfoils.

At the time these calculations were made, the multiple time-step ice accretion used in the single-element study was not available for multiple-element airfoils, so the ice accretion was limited to a single time step. However, LEWICE was capable of reading in multi-block flowfield solutions, so an overset chimera grid approach was taken. 


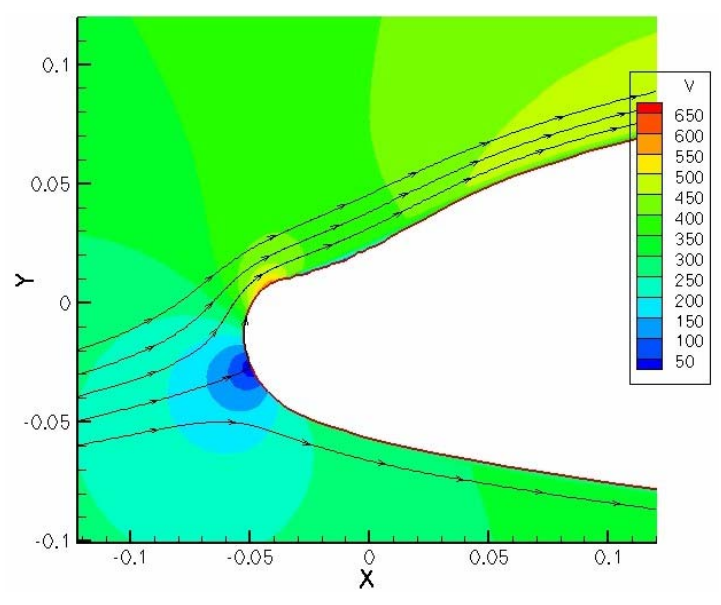

Figure 3. Total Velocity (LEWICE-derived shape)

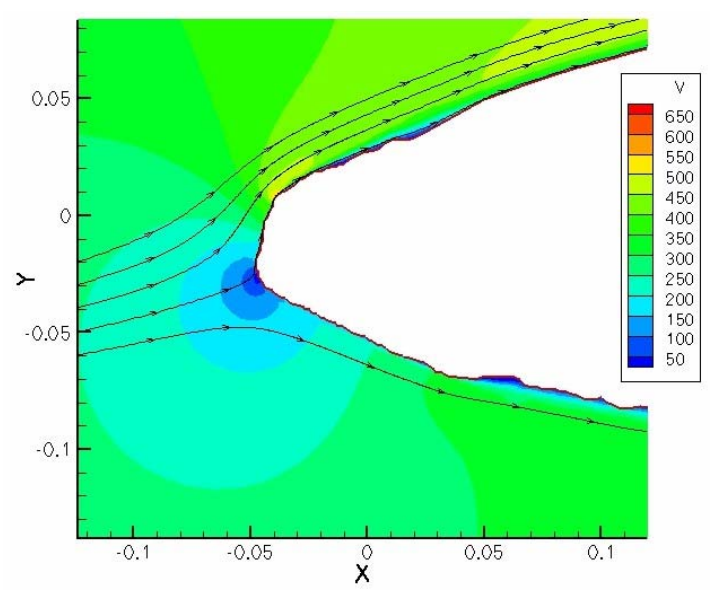

Figure 5. Total Velocity (Experimental Shape)

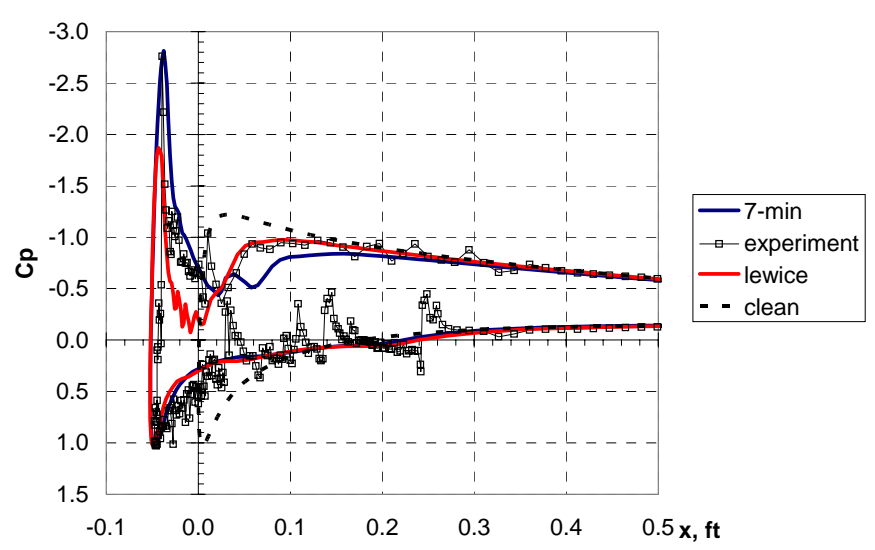

Figure 7. NACA 0012 Pressure Coefficient

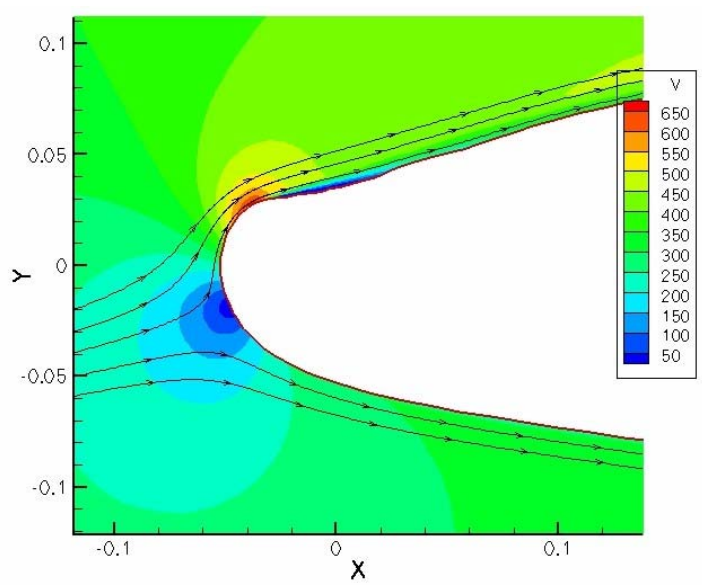

Figure 4. Total Velocity (ICEG2D-derived shape)

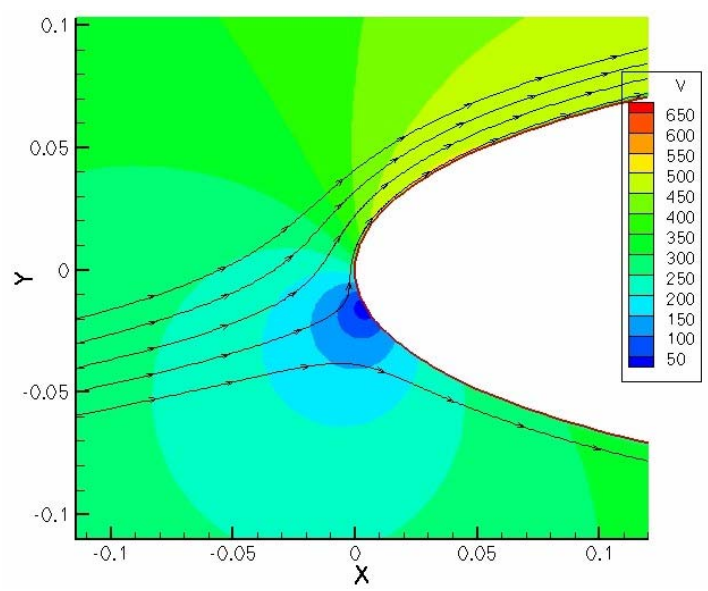

Figure 6. Total Velocity (Clean Airfoil)

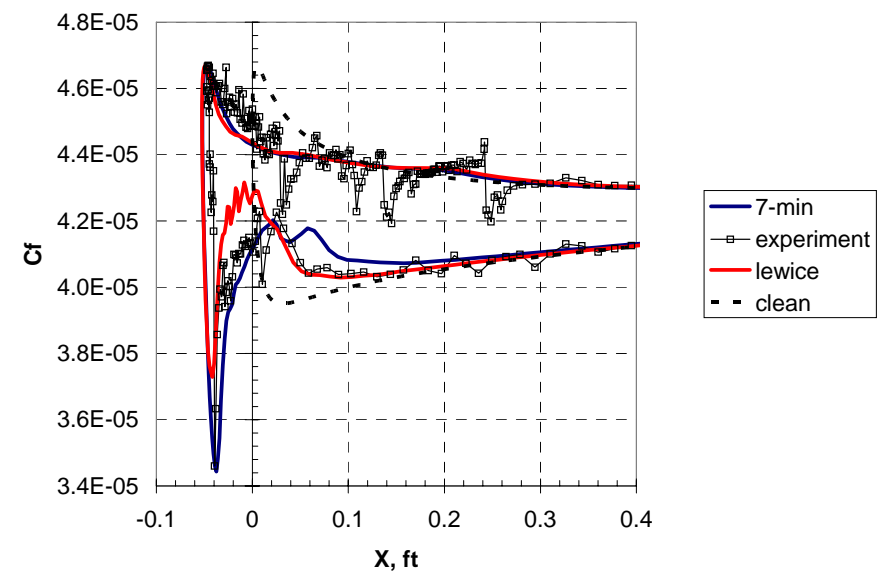

Figure 8. NACA0012 Skin Friction Coefficient 
Conditions corresponding to Case 11 (a multi-element case) in the LEWICE user's manual were selected, with one exception: a monodisperse droplet distribution was used as opposed to a Langmuir distribution. Otherwise, the conditions were the same. Freestream velocity was $88.5 \mathrm{~m} / \mathrm{sec}$, corresponding to a Mach number of 0.27 . MVD was $20 \mu$ and LWC was $0.60 \mathrm{~g} / \mathrm{m}^{3}$. Angle of attack was 8.0 degrees. The icing exposure time was 6 minutes at a freestream temperature of $268.15 \mathrm{~K}$.

The process by which the multi-element ice shape was calculated consisted of the following steps: create x.y geometry files for the slat, main element and flap; generate 2D grids for slat, main element and flap using ICEG2D tools; convert grid $(* . g r d)$ files to WIND $(* . c g d)$ format using the WIND utility $c f c n v t$; modify slat and flap $c g d$ files using the WIND utility cfsubset; combine slat, main and flap grids into one $c g d$ file using $c f c n v t$; create holes/fringes/overlaps and assign boundary conditions using gman; scale the grid; run the flow solver; monitor convergence; post-process the solution; and enter the flow solution into the 2D version of LEWICE.

The geometries for the slat, main element and flap were entered separately into the point-distribution and gridgeneration modules using ICEG2D in interactive mode. Keeping the overall topology in mind, different values were used to create the slat and flap grids, as shown in Table 2 . This produced essentially three different single-element airfoils which then had to be combined into a single grid. The 2D grid for the main element was used as the background grid.

Conversion of the ICEG2D grid files into $c g d$ format made use of the existing WIND utility, cfcnvt. The doubleprecision grid files were in Plot3D ASCII format, with the multi-zone, 2D and I-BLANK flags active. This step was necessary for all three elements.

\begin{tabular}{|l|c|c|c|}
\hline & Slat & Main element & Flap \\
\hline distOuterBoundary & 0.5 & 15.0 & 0.5 \\
\hline nLayers & 100 & 100 & 100 \\
\hline distWake_nl & 0.5 & 14.0 & 0.5 \\
\hline
\end{tabular}

Table 2. Grid Generation Inputs for Multi-element Airfoil.

The utility $c f s u b s e t$ was then used to trim the outer I and $\mathrm{J}$ grid lines in the flap and slat grids. The gen grid command in ICEG2D was found to have difficulties converging if the grid boundaries were set too close to the airfoil. The flap grid should not overlap the slat grid at all, and vice-versa, so cropping was required. The flap and slat zones were trimmed so that both were totally enclosed by the main grid, yet neither intersected the main body by more than a few grid points in the interior (if any). It was also necessary not to trim so much that they didn't have some overlap between the intended holes (ie. the fringe) and the outer zone boundary. Some engineering judgement was involved in selecting the I and $\mathrm{J}$ indices which were to remain after cropping. These indices were related to but not the same as the cutting surfaces that would used in gman in a later step. A $\mathrm{J}$ index of approximately 0.25 to 0.50 chord lengths and I indices approximately 5-10 grid points aft of the trailing edge were found to be sufficient. This step involved the most user intervention and would likely be the most difficult to automate, but was necessary to prevent undefined points in coupled boundaries in the next step.

The slat, main and flap grids were then combined into a single grid in WIND $c g d$ format using the cfcnvt utility. By convention, the main element was set as zone 1 , the slat as zone 2 and the flap as zone 3 . The grid is shown in Figure 9.

The most involved step was the creation of fringes, overlaps and boundary conditions in the gman utility. The process used for the three-element airfoil was similar to that used

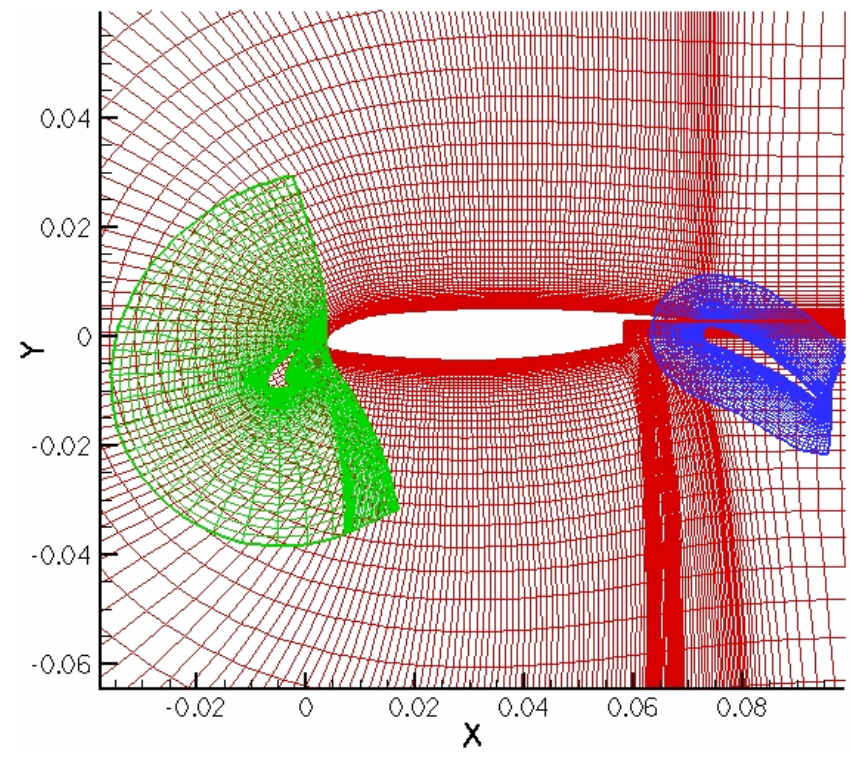

Figure 9. Multi-Element Airfoil Grid 
for an airfoil with flap in the NPARC Validation Archive ${ }^{12}$. The selection of cutting surfaces and subareas for boundary conditions was practically determined iteratively. The I indices to be used as cutting surfaces were within one grid point of the trailing edge or else on the trailing edge. The $\mathrm{J}$ index used as a cutting surface must be somewhat less than the maximum $\mathrm{J}$ index remaining after cropping.

The automatic grid generator in ICEG2D worked best when the airfoil geometry was given in terms of the unit chord, in other words the trailing edge was at $\mathrm{x}=1$ in the $\mathrm{x}, \mathrm{y}$ geometry file $\left({ }^{*} . \operatorname{cln}\right)$. It will work otherwise, for example, using wind-tunnel or full-scale geometries. However, the default values are based on a chord-normalized geometry, which will result in an improper Reynold's Number in the flow solver unless the grid is scaled. In order to match Reynold's number, the grid was scaled up from chord units to physical units (inches) using the global scale option in gman. Because LEWICE operates in chord-normalized dimensions, a later conversion would become necessary.

Since only the point-distribution and grid-generation modules of ICEG2D were used in the multi-element case, a WIND input file had to be created. A grid of 50,000 points took approximately 8-10 hours to reach a converged solution on an Origin SGI. This corresponds to roughly 16-20K iterations.

Post-processing the solution first required a conversion from $c f l$ to PLOT3D format, using the cfpost utility. A second program, a LEWICE utility specific to multi-element airfoils, was then required to convert the standard PLOT3D solution to LEWICE format. In addition, this utility performed several other functions. The flow solution had to be converted to appropriate physical units and the grid was also converted back to chord units. The three zones were re-ordered to reflect LEWICE input requirements. This convention required that the element geometry files be entered into LEWICE in the following order: slat, then main element, then flap. The viscous solution and grid files must also be renamed in order for LEWICE to accept them as inputs. Although it was not necessary in this case, binary to ASCII conversion is necessary if transferring the viscous WIND solutions to a PC rather than an SGI for running LEWICE.

For multi-element geometries using viscous flowfield solutions, LEWICE cases currently only accept single time-step and single drop-size distributions. LEWICE still requires a basic geometry file to run, even when using a viscous solution. The geometric input files should correspond exactly to the surface definition in the grid files, ie. no offsets or smoothing to approximate surface streamlines should be made.

The ice shapes predicted for the multielement slat from both viscous and potential flow are shown in Figure 10, along with the experimental data. The predictions did not appear to be completely reliable, and thus further investigation is required. The discrepancy here is almost certainly due to the monodispersed droplet distribution that was used. Even at zero degrees angle of attack, the slat element (zone 3) did not converge as well as the upstream elements in zones 1 and 2 . There may have been some unsteadiness involved, and improvements to the overall zone

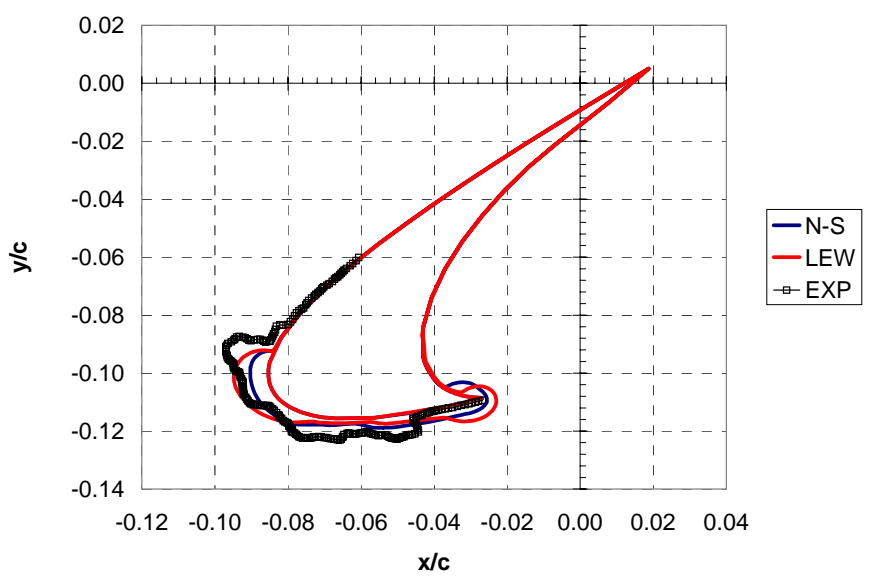

Figure10. Multi-Element Ice Shape (Slat) topology are likely required.

It now appears feasible to automate the LEWICE suite of codes to provide for multiple time-step ice accretions on multi-element airfoils. However, additional improvements to the suite of computational tools are required before the process can be automated. These improvements include more robust tools for crossing between computing platforms, a multi-element capability for the automated grid generator, and full implementation of all LEWICE drop-size and droplet distribution capabilities in the viscous flow solution mode. 


\section{References}

${ }^{1}$ Wright, William B., "User Manual for the NASA Glenn Ice Accretion Code LEWICE,” NASA CR-2002-211793, August 2002.

${ }^{2}$ Thompson, David S., and Soni, Bharat K.,., "ICEG2D- An Integrated Software Package for Automated Prediction of Flow Fields for Single-Element Airfoils With Ice Accretion,” NASA CR-2000-2099914, February 2000.

${ }^{3}$ Thompson, David S., and Soni, Bharat K., "ICEG2D: A Software Package for Ice Accretion Prediction," AIAA 2003-1070, January 2003.

${ }^{4}$ Bush, R.H., Power, G.D., and Towne, C.E., "WIND: The Production Flow Solver of the NPARC Alliance," AIAA 19980935, January, 1998.

${ }^{5}$ Spalart, P.R., and Allmaras, S.R., “A One-Equation Turbulence Model for Aerodynamic Flows,” AIAA 1992-0439, January, 1992.

${ }^{6}$ Shim, Jeonghwan, Chung, June, and Lee, Ki D., “A Comparison of Turbulence Modeling in Flow Analysis of Iced Airfoils," AIAA 2000-3920, January 2000.

${ }^{7}$ Chien, K., "Predictions of Channel and Boundary-Layer Flows with a Low-Reynolds-Number Turbulence Model," AIAA Journal, Vol. 20, No.1, January, 1982.

${ }^{8}$ Wright, William B., and Chung, James, "Correlation Between Geometric Similarity of Ice Shapes and the Resulting Aerodynamic Performance Degradation- A Preliminary Investigation Using WIND,” AIAA 2000-0097, January 2000.

${ }^{9}$ Chung, James, Reehorst, Andrew, Choo, Yung, Potapczuk, Mark and Slater, John, "Navier-Stokes Analysis of Flowfield Characteristics of an Ice-Contaminated Aircraft Wing,".

${ }^{10}$ Potapczuk, Mark G., and Berkowitz, Brian M., "An Experimental Investigation of Multi-Element Airfoil Ice Accretion and Resulting Performance Degradation," NASA TM 101441, 1989.

${ }^{11}$ Shin, Jaiwon, Wilcox, Peter, Chin, Vincent, and Sheldon, David, "Icing Test Results on an Advanced Two-Dimensional High-Lift Multi-Element Airfoil,” NASA TM 106620, 1994.

${ }^{12}$ NPARC Alliance Validation Archive, http://www.grc.nasa.gov/WWW/wind/valid/nlrflap/nlrflap.html 


\begin{tabular}{|c|c|c|}
\hline \multicolumn{2}{|c|}{ REPORT DOCUMENTATION PAGE } & $\begin{array}{l}\text { Form Approved } \\
\text { OMB No. 0704-0188 }\end{array}$ \\
\hline \multicolumn{3}{|c|}{$\begin{array}{l}\text { Public reporting burden for this collection of information is estimated to average } 1 \text { hour per response, including the time for reviewing instructions, searching existing data sources, } \\
\text { gathering and maintaining the data needed, and completing and reviewing the collection of information. Send comments regarding this burden estimate or any other aspect of this } \\
\text { collection of information, including suggestions for reducing this burden, to Washington Headquarters Services, Directorate for Information Operations and Reports, } 1215 \text { Jefferson } \\
\text { Davis Highway, Suite 1204, Arlington, VA 2202-4302, and to the Office of Management and Budget, Paperwork Reduction Project (0704-0188), Washington, DC 20503. }\end{array}$} \\
\hline 1. AGENCY USE ONLY (Leave blank) & \begin{tabular}{|c|c|} 
2. REPORT DATE & 3. \\
March 2005 &
\end{tabular} & $\begin{array}{l}\text { D DATES COVERED } \\
\text { echnical Memorandum }\end{array}$ \\
\hline \multicolumn{2}{|c|}{$\begin{array}{l}\text { The Influence of Viscous Effects on Ice Accretion Prediction and Airfoil } \\
\text { Performance Predictions }\end{array}$} & 5. FUNDING NUMBERS \\
\hline $\begin{array}{l}\text { 6. AUTHOR(S) } \\
\text { Richard E. Kreeger and Wil }\end{array}$ & B. Wright & WBS-22-728-41-10 \\
\hline $\begin{array}{l}\text { 9. SPONSORING/MONITORING AGEI } \\
\text { National Aeronautics and Sp } \\
\text { Washington, DC 20546-00 }\end{array}$ & $\begin{array}{l}\text { NAME(S) AND ADDRESS(ES) } \\
\text { Administration }\end{array}$ & $\begin{array}{l}\text { 10. SPONSORING/MONITORING } \\
\text { AGENCY REPORT NUMBER } \\
\text { NASA TM-2005-213593 } \\
\text { AIAA-2005-1373 }\end{array}$ \\
\hline
\end{tabular}

Prepared for the 43rd Aerospace Sciences Meeting and Exhibit sponsored by the American Institute of Aeronautics and Astronautics, Reno, Nevada, January 10-13, 2005. Richard E. Kreeger, NASA Glenn Research Center; and William B. Wright, QSS Group, Inc., 21000 Brookpark Road, Cleveland, Ohio 44135. Responsible person, Richard E. Kreeger, organization code RTI, 216-433-8766.

\begin{tabular}{|l|l}
\hline 12a. DISTRIBUTION/AVAILABILITY STATEMENT & 12b. DISTRIBUTION CODE \\
Unclassified - Unlimited & \\
Subject Categories: 02 and 03 & \\
Available electronically at http://gltrs.grc.nasa.gov & \\
This publication is available from the NASA Center for AeroSpace Information, 301-621-0390. &
\end{tabular}

13. ABSTRACT (Maximum 200 words)

A computational study was conducted to evaluate the effectiveness of using a viscous flow solution in an ice accretion code and the resulting accuracy of aerodynamic performance prediction. Ice shapes were obtained for one single-element and one multi-element airfoil using both potential flow and Navier-Stokes flowfields in the LEWICE ice accretion code. Aerodynamics were then calculated using a Navier-Stokes flow solver.

\begin{tabular}{|c|c|c|c|}
\hline \multicolumn{3}{|l|}{ 14. SUBJECT TERMS } & $\begin{array}{c}\text { 15. NUMBER OF PAGES } \\
13\end{array}$ \\
\hline NSN 7540-01-280-5500 & & & $\begin{array}{l}\text { andard Form } 298 \text { (Rev. 2-89) } \\
\text { scribed by ANSI Std. Z39-18 } \\
-102\end{array}$ \\
\hline
\end{tabular}



